\title{
Erratum to: Inhibition of Candida albicans virulence factors by novel levofloxacin derivatives
}

\author{
Raja Mohamed Beema Shafreen • \\ Subramanian Muthamil • \\ Shunmugiah Karutha Pandian
}

Published online: 9 July 2014

(C) Springer-Verlag Berlin Heidelberg 2014

\section{Erratum to: Appl Microbiol Biotechnol}

DOI 10.1007/s00253-014-5719-2

The original publication unfortunately captured an incorrect presentation of author names. It was published as "Beema Shafreen Raja Mohamed", "Muthamil Subramanian" and "Karutha Pandian Shunmugiah". The correct presentation is given above.

The online version of the original article can be found at http://dx.doi.org/ 10.1007/s00253-014-5719-2.

R. M. Beema Shafreen $\cdot$ S. Muthamil $\cdot$ S. Karutha Pandian $(\bowtie)$

Department of Biotechnology, Alagappa University, Science

Campus, Karaikudi 630004, Tamil Nadu, India

e-mail: sk_pandian@rediffmail.com 